\title{
PATTERNS OF NAMING OBJECTS AND ACTIONS IN CHILDREN WITH WORD FINDING DIFFICULTIES ${ }^{12}$
}

Julie E. Dockrell, ${ }^{3}$

Psychology and Special Needs,

Institute of Education,

20 Bedford Way,

London WC1H 0AL

David Messer,

Psychology Division,

University of Hertfordshire,

College Lane, Hatfield AL10

Rachel George

Division of Psychology,

University of Central Lancashire

Preston, Lancashire PR1 2HE

\footnotetext{
${ }^{1}$ The work reported here was funded by a Wellcome Trust grant to Julie Dockrell and David Messer. We are grateful to Gillie Wilson for collecting part of the data presented here and all the children who participated. Two anonymous reviewers and the editor have provided detailed and constructive criticisms.

${ }^{2}$ A proportion of the data on naming objects was presented at the Child Language seminar 1997 and published in the conference proceedings and a proportion of the comparative data between objects and actions was presented at the International Congress for the Study of Child Language 1999.

3 Address for correspondence
} 


\section{Abstract}

Children who experience difficulties in naming are described as having word finding difficulties (WFDs). In the present study 31 children with WFDs were identified through a wider survey of educational provision for those with language and communication difficulties. The children were included if they were between 6;4-7;10 years, had normal non-verbal intelligence, no major articulation difficulties and had WFDs as diagnosed by the Test of Word Finding Difficulties (TWF, German, 1989). Three control groups were identified who were matched on: chronological age $(\mathrm{N}=31)$, naming age $(\mathrm{N}=31)$ and level of receptive grammar $(\mathrm{N}=31)$. Children's comprehension of words, accuracy of naming and latency to name were assessed for numerals, letters and pictures of objects and actions. Half the pictures presented were high frequency items and half were low frequency items. The children with WFDs formed a heterogeneous group with respect to other language measures with the primary defining feature being their poor performance in word retrieval and their poor performance on a semantic fluency test. No differences were found between the children with WFDs and their age-matched peers when naming letters and numerals or in the comprehension of objects and actions. In contrast, the accuracy and latency of naming were significantly worse than that of age matched peers. Accuracy of naming was equivalent to that of the language matched peers and error patterns also were similar. However, the children with WFDs were the slowest to provide responses and for naming high frequency objects this difference approached significance in comparison to language matched peers $(\mathrm{p}=.052)$. The findings point to the importance of using appropriate control groups, and are discussed in relation to the idea that WFDs are caused by impoverished semantic representations. 


\section{INTRODUCTION}

There is increasing appreciation of the important role of the lexicon in language development and the acquisition of literacy abilities (Catts \& Kamhi, 1999). Difficulties in accessing the lexicon are likely to compromise children's communication and their ability to acquire academic skills (Snyder \& Godley, 1992), and these problems are especially likely to be experienced by children who are described as having Word Finding Difficulties (WFDs). These children are characterised as having long delays in word retrieval, a high occurrence of circumlocutions and word substitutions (German \& Simon, 1991). However, the causes of WFDs remain uncertain because of the variety of samples studied and the limited types of comparison groups that are employed. Therefore, this investigation has been designed to address two key issues, (1) the selection of an objectively identified sample of children with WFDs who are compared with an appropriate set of matched comparison groups to determine the nature of WFDs, and (2) the use of a range of systematically identified targets to extend our understanding of WFDs across a larger range of lexical items.

Rationale for the Choice of Groups. There have been a number of approaches to the study of WFDs. Some researchers have focussed on a clinical population of language impaired children and have investigated WFDs in that population. Indeed it has been argued that WFDs do not occur in isolation from language disabilities (Kail, Hale, Leonard \& Nippold, 1984; Wiig, Semel \& Nystrom 1982) or other learning disabilities (Kail \& Leonard, 1986). Studies within this tradition have found that children who have specific problems with their expressive language have associated WFDs both in tests and in spontaneous discourse. Findings also indicate that WFDs are not exclusively identified in populations with specific language impairments. WFDs have also been identified in children with learning difficulties (German, 
1979, 1985; Wiig \& Semel, 1975) and with dyslexia (Rudel, Denckla \& Broman, 1981; Swan \& Goswami, 1997; Wolf \& Segal, 1992).

Investigations that are concerned with WFDs in special populations usually do not identify whether or not children have WFDs with the use of objective standardised tests. As a result, there often is uncertainty about the proportion of children with or without WFDs in such samples and there are, therefore, difficulties in drawing conclusions about the nature of WFDs per se. If one is interested, as we were, in the general characteristics of a group of children who all have objectively defined WFDs then an alternative method of selection is needed. For these reasons two selection procedures were instituted. First, speech and language therapists and teachers identified children in language support services who had marked WFDs. Then the children were assessed using the Test of Word Finding Difficulties (TWF, German, 1989) to confirm the therapists' diagnosis. This test allows both the identification of word finding difficulties in relation to age matched peers and where necessary a procedure to prorate performance in relation to the child's level of lexical comprehension. Additional entry criteria were average non-verbal intelligence, no major articulation problems that could have affected word production, and no other hearing or neurological disabilities. These selection criteria resulted in the identification of a clearly delineated sample of children with WFDs who possessed average non-verbal abilities and no articulation problems.

The performance of children with WFDs has been, in almost all previous studies, either examined in isolation or compared to chronological age matches. This provides a basis for establishing whether certain of the abilities of children with WFDs are below what would be expected based on their age. However, such comparisons fail to take into account the level of language in the samples. Since children with language difficulties will often have a smaller 
vocabulary than their peers (Leonard, 1988; Rescorla \& Schwartz, 1990; Rice, 1991), it is important to consider their word-finding skills in relation to this and other indicators of language capacity. If children with WFDs perform significantly worse than language matched controls on a task this will identify an area of performance where they experience difficulties beyond that expected for their language level (Dockrell, Messer \& George, 2000). Such comparisons should help to identify the essential characteristics of WFDs and help understand the causes of WFDs by, for example, allowing differentiation between 'developmental immaturities' in word-finding and alternative explanations in terms of phonological or semantic factors (McGregor, 1997). Thus, in this study we chose the following matches: (i) a chronological age comparison group (CA) that was controlled for non-verbal ability, (ii) a naming age comparison group (NA) who were at a similar level of picture naming ability as the children with WFDs, and (iii) a group matched for syntactic comprehension who were at a similar level of receptive grammar (RG) as the children with WFDs. In all cases, reliable and valid measures standardised on the local population were chosen to identify controls. By employing an objective measure of WFDs and a greater range of comparison groups, we aimed to identify the language difficulties of a well defined population of children with WFDs. In addition information about the phonological skills of the WFDs group were collected to provide descriptive information about these skills. Our particular interest was the identification of differential performance across tasks with the aim of elucidating patterns of delay and difference in the performance of children with WFDs.

Rationale for the Choice of Test Items. There are few developmental models of WFDs (but see Constable, Stackhouse \& Wells, 1997) and discussions about the causes of WFDs have tended to focus on either phonological or semantic deficits (see also Menyuk, 1975; 
Nippold, 1992 for ideas about retrieval problems). The view that WFDs are caused by semantic deficits has involved the suggestion that the lack of elaborate semantic representations makes it more difficult for children to retrieve words (Kail \& Leonard, 1986; Lahey \& Edwards, 1996, 1999; McGregor \& Leonard, 1989; McGregor \& Windsor, 1996). In contrast, other accounts suggest that phonological representations are more difficult to access and/or that the transfer of information between the semantic and phonological systems is impaired (Constable et al., 1997). To address these issues and to extend the range of lexical items employed in the study of WFDs we presented children with tasks that involve: (i) naming objects (as in most previous studies); (ii) naming actions; (iii) naming single-numerals and letters, and (iv) naming both high and low frequency items. The rationale for these choices is set out below.

Studies of WFDs have rarely considered children's naming of actions even though there are indications that naming actions involves different processes to the naming of objects. Gentner (1981) suggests that the naming of verbs is delayed relative to that of objects, although the differential advantage for naming objects above actions has been called into question by Davidoff and Masterson, (1995/6). McGregor (1997), in one of the few studies of the naming of actions in children with WFDs, compared their performance with age matched peers using the sub-tests from the Test of Word Finding Difficulties (TWF, German, 1989). The performance of children with WFDs appeared delayed across both word classes, with some evidence for a differential pattern of responses. Interestingly, in adults, clearer differences in error patterns have been found for nouns and verbs (Davidoff \& Masterson, 1995/6). There also appears to be evidence for differences in performance according to the types of verb studied. Davidoff and Masterson (1995/6) found that actions involving intransitive verbs were more difficult to name than those involving transitive verbs. The authors argue that the 
unavailability of associated representations might make retrieval of intransitive verbs more difficult than transitive verbs. As there is evidence that the semantics of verbs differ from those of nouns, and that verbs may be a particular problem area for children with general language problems, these items may pose greater problems for children with WFDs. Given these concerns and findings it was decided to investigate the naming of actions and employ both transitive and intransitive items.

The nature of semantic representations is likely to vary across conceptual domains (Braisby \& Dockrell, 1999; Markman, 1989; Soja, 1994) and by corollary across lexical items. Actions and objects denote complex concepts, whereas single numerals and alphabetic letters involve concepts with low semantic complexity. We, therefore, also investigated the naming of letters and single numerals, as well as the naming of objects and actions. By selecting these different types of lexical items, we aimed to investigate whether children with WFDs, in comparison to language age matches, find certain types of lexical items especially difficult to produce. Furthermore, the presence of differences between word class could provide support for the idea that the impoverished nature of children's representations contributes to WFDs. Difficulties in naming objects and actions and not letters and numerals would suggest that the semantic complexity of the items were critical.

When investigating naming it also is important to consider word frequency. Word frequency is associated with quicker and more accurate responses when picture naming and these effects are typically described as a consequence of changes to lexical representations that affect the access process. Consequently, if children with WFDs experience a similar word frequency effect to typically developing peers this would suggest that their representations are influenced, in a similar manner to typical children, by the amount of exposure to words. In 
contrast, a lack of a frequency effect would implicate more general problems with access irrespective of the nature of the representations.

A similar argument can be developed that the age when a lexical item is acquired has an influence on children's naming. Earlier acquired lexical items are likely to be better established than later acquired ones. Unfortunately there are insufficient data about the age of acquisition of lexical items to construct the appropriate stimuli sets. However, data about the age of acquisition of the lexical items used in the current study are presented where available in the methods section.

Studies of word frequency that involve children with naming difficulties have produced contradictory findings. On a picture naming task, Denckla and Rudel (1976) reported that with low-frequency words, children with dyslexia produce more errors and longer response times than children with language difficulties. German $(1979,1984)$ published similar findings for children with language difficulties and children with learning disabilities. In contrast, Wiig et al (1982) reported that the picture naming of high frequency words differentiated normal and language disordered children but Wolf (1980) found no frequency effects. All these findings point to the importance of considering this dimension in relation to WFDs. However, estimating word frequency for children's oral language is complex. Studies with adults tend to use estimates of printed word frequency; such a measure would be inappropriate for young children who cannot read, children who are at the early stages of literacy acquisition or children whose language may be delayed. Consequently, several methods of selecting high and low frequency words were employed in this study.

To summarise, one of the aims of the present study was to identify a clearly delineated group of children with objectively defined WFDs using the Test of Word Finding Difficulties 
(TWF, German, 1989). The performance of these children was compared with a group of typical children matched for chronological age (CA), a group who have similar productive language (NA), and a group matched for grammatical comprehension (RG). As a result, it should be possible to identify language delays in children with WFDs that are below those expected for their chronological age, and identify specific language delays which go beyond those expected for the children's level of language. These comparisons can give a more detailed picture of the strengths and weaknesses of children with WFDs. In addition, the comparisons should contribute to understanding the underlying cause of the difficulties of these children.

\section{METHODS}

\section{Participants}

The total sample consisted of 124 children attending schools, language support services and nurseries in the South East of England. Thirty-one children who experienced word-finding difficulties participated in the study, mean age 7;1 [range 6;4-7;10]. The lower age-band was determined by the standardisation of the TWF and the upper age band was used to minimise the variability in the sample in terms of educational opportunities (such as access to the National Curriculum) and other developmental experiences. The children were identified following a wider survey of educational provision for children with word finding difficulties (Dockrell, Messer, George \& Wilson, 1998). Schools were sampled where professionals had reported that they had children with primary word-finding difficulties. Children were drawn from 11 different language support services, nine of these were attached to mainstream schools. Once identified by the professional (teacher or speech and language therapist), children were required to meet the following the criteria for inclusion in the WFDs sample: (1) to fall within an eighteen-month age band $(6 ; 4 .-7 ; 10) ;(2)$ demonstrate word-finding difficulties relative to their comprehension 
skills as identified by the Test of Word Finding Difficulties (TWF, German, 1989); (3) have age appropriate (at or above the $25^{\text {th }}$ centile) non-verbal abilities as measured by Raven's matrices (1983) and, (4) have no marked difficulties in articulation as measured by the Edinburgh Articulation Test (EAT, Anthony, Bogle, Ingram \& McIsaac, 1971). The articulation criterion was operationalised as not scoring below - 1SD for the age group 5;5-6;0 (the test ceiling). The minimum EAT raw score was 49, the mode and median for the sample was 60 . A raw score of 60 is equivalent to a standard score of 106 for the age range 5;9-6;0.

The children in the control groups were drawn from similar geographical areas to the children with WFDs and where possible were attending the same school. All the control children attended state mainstream educational provision. None of the children had identified special educational needs or English as an additional language. Children in the language age control groups were required to achieve a typical score on the matched language measure (see below) that is within a three month band of their chronological age.

The 31 children in each of the three control groups were individually matched to the children in the WFDs group. Each child in the chronological age (CA) control group had a birthday within 3 months of a matched child in the target sample and their Matrices score was in the same centile band. A naming age matched group (NA) was identified using the British Abilities naming scale (BAS, Elliot, Smith, \& McCulloch, 1997). Each child in this control group had an ability score that was (1) age appropriate and (2) exactly matched to a child in the WFDs group. The children's mean naming age was 4;10. A Reception of Grammar matched group (RG) was identified using scores from Test of Reception of Grammar scores (TROG, Bishop, 1989). Each child in this control group had a TROG score that was (1) age appropriate and (2) the raw score was matched exactly to a child in the WFDs group. The age equivalent 
score of each child in this control group was exactly matched to those of the children with WFDs. The children's mean reception of grammar age was 5;9. Table 1 presents the group scores on the relevant matched measures.

\section{INSERT TABLE 1 ABOUT HERE}

\section{Description of Language skills of the children with WFDs}

The children with WFDs were not a homogeneous group with respect to language measures. Although all had word-finding problems as defined by clinicians and the Test of Word Finding Difficulties (TWF, German, 1989), other language skills showed a marked variation. Assessment of their phonological skills on the Phonological Assessment Battery (PhAB: Fredrickson, Frith \& Reason, 1997) revealed that the majority of the children had low scores on the Fluency measures on the $\mathrm{PhAB}$ (for these tasks children are required to generate as many words as possible according to phonological or semantic criteria) and notably low scores for semantic fluency (for this measure all children had scores at least $1 \underline{\mathrm{SD}}$ below the mean with 77 per cent of the children scoring $2 \underline{\mathrm{SD}}$ below the mean). These fluency results corroborate clinical descriptions of this population. In contrast mean scores on the other phonological measures (rhyme and alliteration) did not fall below one standard deviation of the mean, with an average standardised score of 85 for both (range 69 - 101 for alliteration and 69 - 112 for rhyme). Statistical analyses were conducted to investigate whether sub-groups could be identified based on the other language scores, such as the TROG. No homogeneous subgroups were identified. This failure to identify prominent sub-groups, together with the careful 
matching of the control groups on key language measures, helps to justify the decision to carry out analyses on the whole of the sample of children with WFDs.

\section{Materials}

The complete set of naming stimuli consisted of 40 coloured drawings of objects and 20 coloured drawings of actions, together with 5 single digit numerals and 5 letters. The items that were used are presented in Appendix 1. The drawings chosen were ones commonly used successfully in a pre-school speech and language unit and were therefore deemed appropriate for the population. The pictures were scanned into a specially designed computer programme. In the comprehension tests four pictures were presented on the screen. The location of the correct picture on the computer screen varied randomly across trial items. Three foil pictures were chosen to allow different error patterns to be investigated: a semantic foil (an item from the same semantic domain), a phonological foil (an item starting with the same sound pattern), and finally an irrelevant foil. Frequency was controlled across foil items.

The main task of the participants was to name this set of pictures as quickly as possible. To provide a controlled stimulus set we restricted, as far as possible, the domains, frequencies, picturability and length of the items chosen. Object names were selected from the domains of animals, body parts, clothes and household items. These domains were chosen to: span natural kinds and artifacts; provide sufficient differentiation in frequency ranges; be familiar and interesting to children, and contain a sufficient number to fulfill the additional criteria for the items. A set of 'actions' was selected to include both transitive and intransitive verbs. For each of these six domains an equal number of high and low words frequency words were selected. The frequency selection was from Francis and Kucera (1982) as a best 
approximation, and items were only included if they also were contained in at least one of three primary grade sources books (Burroughs, 1957; Gates, 1935; Edwards \& Gibbon, 1973). It was not possible to match for frequencies across categories. However, frequency ranges did not overlap, thus the lowest frequency count for a high frequency item was 46 and the highest frequency count for a low frequency item was 17. In addition low frequency items were excluded if they were contained in the top 1,000 words of Burroughs (1957), as were items of low picturability.

The age of acquisition could be identified for 32 of the 40 object names using a combination of databases (Gilhooly \& Logie, 1980; Morrison, Chappell \& Ellis, 1997), but no data could be found about the age of acquisition for any of the verbs. Data were available for all

high frequency objects with a mean age of acquisition of 25.4 months (range 15.3-47.6) and 12 low frequency items with a mean age of acquisition of 38.6 (range 17.7-74.1). From these figures it would appear that all high frequency items and most low frequency items had an age of acquisition of below four years (see Appendix 1).

\section{Procedure}

Each child was tested individually. Children's naming and comprehension of the test stimuli were assessed in a single session. All children completed the naming task before the comprehension task. Items were randomly presented to each child for naming and there were five preset random orders for the comprehension items. Object naming occurred before action naming.

The stimuli for both naming and comprehension were presented on a portable computer that recorded accuracy and latency. In parallel, a tape recorder was used to capture oral responses for later error analysis and an ongoing written record was kept. Children were 
provided with five practice items for each condition. No feedback was provided on the test items. Children appeared to enjoy the task. Naming and comprehension tasks were always completed in a single session.

\section{Error analysis}

Errors were coded to capture the full range of responses made by the children. These included semantic errors, phonological errors, don't know and other errors. Semantic errors were deemed to be substitutions that preserved the general features of the meaning of the word and were nearly always members of the same grammatical form class e.g. 'mug' for 'cup' or 'knitting' for 'sewing'. In contrast phonological errors were those which preserved either the initial or end pattern of the target item e.g. 'bog' for 'dog' or 'strong' for 'stroke. A don't know response was recorded if the child either said they did not know or indicated non-verbally that they did not know. Other errors included circumlocutions, nonsense words, descriptions of the items in the picture, or naming responses where links between target and answer were indirect or thematic e.g. 'desert' for 'camel' or 'drinking' for 'sweating'. It was, however, possible for children to provide answers that were deemed both phonological and semantic errors or 'other' and phonological. In such cases responses were coded in both error categories. Two investigators coded a subsample of each group's responses. Any disagreements in coding were scored by a moderator until agreement on codes was achieved. The two investigators then coded the remaining errors. Any errors that had not been discussed or identified in the initial coding were considered by the team again and then coded. 


\section{RESULTS}

The results are presented in four sections. Section 1 examines the children's performance with numerals and letters. These data are considered before the data concerning objects and actions, because interpretation of these findings is more straightforward. Section 2 compares the performance of the four groups across the remaining naming domains. The initial analysis includes data for both objects and actions and allows a comparison of the two word classes. Because differing patterns in performance were identified for objects and actions, separate group comparisons were performed for these items. The between group differences for object names are described in section 3, and similar analyses for actions are presented in section 4. In all cases the ANOVA analyses use group as a between subject factor and the relevant stimulus dimensions as within subject factor.

There is a complex set of differences between groups, stimulus dimensions and assessed response (comprehension, naming and latency). To aid interpretation of the data Table 2 provides a summary of the main differences based on the post-hoc comparisons between groups presented in sections 3 and 4. For letters and numerals the performance of children with WFDs was not significantly different from the CA matches and was usually better than the LA matches (LA refer to the combined pattern for the NA and RG matches when no differences between the language matches occurred). In contrast, for objects and actions there was a marked difference in performance across the three different forms of assessment - comprehension, naming accuracy and latency. 


\section{INSERT TABLE 2 ABOUT HERE}

\section{Section 1: Comprehension and Naming of letters and numerals}

Table 3 presents the findings from the letters and numerals tasks. Separate ANOVAs (involving comprehension, naming accuracy and latency) were conducted on letters and numerals. These revealed that there were significant differences between the groups in terms of comprehension $($ Letters $\mathrm{F}(3,120)=8.094, \underline{\mathrm{p}}<.001$; Numerals $\mathrm{F}(3,120)=5.337, \underline{\mathrm{p}}<.001)$, accuracy $($ Letters $\mathrm{F}(3,120)=10.07, \underline{\mathrm{p}}<.001 ;$ Numerals $\mathrm{F}(3,120)=6.98, \underline{\mathrm{p}}<.001)$ and latency $($ Letters $F(3,120)=3.91, \underline{p}<.001 ;$ Numerals $F(3,120)=2.89, \underline{p}<.05)$. Post hoc tests revealed no significant differences between the children with WFDs and their CA matched peers in comprehension, naming accuracy or latency. Children with WFDs in comparison to the NA matches were significantly more accurate in comprehension (for letters $\underline{p}<.01$ and for numerals $\mathrm{p}<.05$ ) and in naming (for letters $\mathrm{p}<.05$ and for numerals $\mathrm{p}<.001$ ). In terms of the mean latency for both letters and numerals, the groups were ordered as follows: CA, WFDs and then the NA and RG groups. The only significant difference occurred between the NA and CA groups for letters $(\mathrm{p}<.05)$. Thus, when comprehending and naming letters and numerals, children with WFDs were neither less accurate nor slower than typical children of the same age.

\section{INSERT TABLE 3 ABOUT HERE}

\section{Section 2: Overall results, objects and actions}

For objects and actions, the proportion scores for comprehension accuracy, naming accuracy and naming latency are presented in Table 4. In all cases, ANOVA reveal significant differences according to group and frequency. 


\section{INSERT TABLE 4}

As the table shows, all children were highly accurate in their comprehension. The comprehension data were analysed with word class (objects or actions) and word frequency (high or low) as within subject factors and group (CA, NA, RG, \& WFDs) as the between subject factor. There was a significant effect of both word frequency $(\mathrm{F}(1,120)=158.19, \underline{\mathrm{p}}<$ $.001)$ and experimental group $(\mathrm{F}(3,120)=14.86, \mathrm{p}<.001)$ for comprehension, but no main effect of word class. There were significant interactions between group and word frequency $(\mathrm{F}$ $(3,120)=6.78, \underline{p}<.001)$ and word class and word frequency $(F(1,120)=8.14, \underline{p}<.001)$. Thus despite the overall high levels of success, the groups were performing significantly differently and all children performing better with high frequency items.

In the analyses of naming accuracy and naming latency it was decided to eliminate any lexical items which children failed to identify in the comprehension tests in order to establish a set of 'known' items for each child, thus allowing a direct assessment of word finding difficulties. This resulted in different item sets for each child and therefore proportion scores are used in subsequent analyses. Latency scores were tabulated for correct responses only. Using the same design as had been employed for comprehension two further ANOVAs were conducted on accuracy of naming and latency of naming as the dependent variable. For naming accuracy, as with comprehension, there was a main effect for both word frequency $(\mathrm{F}(1,120)=980.82$, $\mathrm{p}<$ $.001)$ and group $(\mathrm{F}(3,120)=10.34, \mathrm{p}<.001)$ with an interaction between word class and group $(\mathrm{F}(3,120)=2.74, \mathrm{p}<.05)$. For latency measures there was a main effect of word frequency $(\mathrm{F}(1,117)=23.41, \mathrm{p}<.001)$, group $(\mathrm{F}(3,117)=4.09, \mathrm{p}<.01)$ and word class $(\mathrm{F}$ $(1,117)=34.30, \underline{p}<.001)$ and an interaction between group and word frequency $(\mathrm{F}(3,117)=$ 
$3.06, \mathrm{p}<.05)$. The differential effect of word class on latency suggests that naming objects and actions involve different processing demands. To explore these differences further post-hoc analyses to test for group and task effects were carried out separately for each word class. These are presented in the next sections, first for objects and then for actions. For each word class there is an examination of comprehension accuracy, naming accuracy, naming latency, and error responses.

\section{Section 3: Objects}

\section{Accuracy of object comprehension:}

Analysis of the full data set for comprehension revealed a significant effect of group $(\mathrm{F}(3,120)=6.296, \underline{\mathrm{p}}<.01)$, word frequency $(\mathrm{F}(1,120)=65.648, \underline{\mathrm{p}}<.001)$ and an interaction between group and word frequency $(\mathrm{F}(3,120)=3.284, \underline{\mathrm{p}}<.05)$. Post hoc Scheffe's tests between the 4 groups of children revealed no differences in the accuracy of comprehension for high frequency items. However, for low frequency items there were differences between groups. The CA control group was significantly better than the two language match groups (NA: $\underline{p}<.01 ; \mathrm{RG:} \underline{\mathrm{p}}<.05$ ). The children with WFDs had intermediate scores and were not significantly different from their NA, RG, or CA peers.

\section{Accuracy of object naming}

Although there was a significant correlation between naming accuracy and comprehension accuracy $(\underline{\mathrm{r}}=.473, \mathrm{~N}=124, \underline{\mathrm{p}}<.001)$ the children accurately named significantly fewer object words than they comprehended $(\underline{t}=-25.27$, df $123, \underline{p}<.001)$. Analysis of the data set of 'known' items revealed that there were significant effects of group $(\mathrm{F}(3,120)=9.04, \underline{\mathrm{p}}<.001)$, word frequency $(\mathrm{F}(1,120)=692.28, \underline{\mathrm{p}}<.001)$ and an 
interaction between group and word frequency $(\mathrm{F}(3,120)=3.20, \mathrm{p}<.05)$. Post hoc

Scheffe's tests between groups revealed that the CA group was performing significantly better than the other three groups for high frequency (WFDs: $\mathrm{p}<.05$; NA: $\mathrm{p}<.01 ; \mathrm{RG}: \mathrm{p}<.01$ ) and low frequency items (WFDs: $\mathrm{p}<.001$; NA: $\mathrm{p}<.001 ; \mathrm{RG}: \mathrm{p}<.05$ ). No other significant differences between the groups were identified.

\section{Latency of object naming}

Mean latencies for correct responses to high and low frequency items are presented in Table 4. There was a significant effect of word frequency $(F(1,120)=9.04 \mathrm{p}<.01)$ and an interaction between group and word frequency $(\mathrm{F}(3,120)=5.05 \mathrm{p}<.01)$. Post hoc Scheffe's tests indicated that the children with WFDs were significantly slower than CA matches for high frequency items $(\mathrm{p}<.01)$ and there was a trend suggesting that they were also slower than their NA matches $(\mathrm{p}=.052)$. There were no significant differences between the NA or RG matches and the CA matched peers for high frequency items and no significant differences between any of the groups for low frequency items.

\section{Error patterns in naming objects}

The analysis of the children's naming accuracy indicated that the CA matched children were producing significantly fewer errors, however, such an analysis does not indicate whether the nature of errors differed across the groups. If the relative frequency of different types of naming errors (semantic, phonological, don't know and other errors) were similar across the 4 groups this would suggest that the language of children with WFDs were developing in a similar manner to typical children. To conduct these analyses the errors for low and high frequency items were combined and a calculation was made of the distribution of error types across total 
errors. Proportions were calculated to allow comparisons between groups and word classes. Object naming errors are presented in Table 5.

As Table 5 shows the overall distribution of error types across the groups was similar, and that semantic errors were the most common of the four types. Comparisons between the groups using a Kruskal Wallis test revealed no significant differences in the proportion of semantic errors $\left(X^{2}=1.10\right.$, df $=3$, ns $)$, don't know responses $\left(X^{2}=1.88\right.$, df $=3$, ns $)$ or other errors produced $\left(X^{2}=.11 \mathrm{df}=3, \mathrm{~ns}\right)$. In contrast the proportion of phonological errors varied significantly across the groups $\left(X^{2}=8.79, \underline{p}<.05\right)$. The WFDs children produced significantly more phonological errors than their CA peers $(U=293, \underline{p}<.01)$ and their $R G$ matches $(U=$ $329, \mathrm{p}<.05)$ but not their NA matches. The distribution of phonological errors within the WFDs group was examined to establish whether individual children were accounting for these responses. This was not the case, phonological errors were distributed across the sample of children with WFDs. Thus, these analyses indicate that children with WFDs made proportionally more phonological errors than their CA matched peers and RG matched peers, but not proportionally more than their NA matched peers did. Overall semantic errors dominate all children's erroneous responses for the object pictures.

\section{INSERT TABLE 5 ABOUT HERE}

\section{4: Actions}

\section{Accuracy of comprehension for actions}

For the accuracy of comprehending actions, an ANOVA of the full data set identified a significant effect of group $(F(3,120)=12.29, \underline{p}<.001)$, of word frequency $(F(1,120)=$ 
$93.54, \underline{p}<.001)$ and an interaction between group and word frequency $(F(3,120)=3.79, \quad \underline{p}<$

.05). Post hoc Scheffe's tests between groups revealed no differences for high frequency actions. However for low frequency actions both the CA control $(\underline{p}<.001)$ and the children with WFDs $(\mathrm{p}<.05)$ were significantly better than the NA group and there was a trend identified suggesting a difference between RG matches and CA matches $(\mathrm{p}=.058)$. Thus, there was no evidence for a difficulty with the comprehension of verbs for children with WFDs.

\section{Accuracy of naming actions}

There was a significant correlation between accurate naming and accurate comprehension $(\underline{\mathrm{r}}=.353, \mathrm{~N}=124, \underline{\mathrm{p}}<.001)$ of actions, but children were less accurate in producing than in comprehending these items $(\underline{\mathrm{t}}=-20.57$, df $=123, \underline{\mathrm{p}}<.001)$. Analysis of the full data set shows that there is a significant group effect $(F(3,120)=8.21, \underline{p}<.001)$, word frequency effect $(\mathrm{F}(1,120)=496.29, \quad \mathrm{p}<.001)$, but no significant interactions. All groups were more accurate on high frequency words. Since there were no significant interactions between group and frequency, high and low frequency results were collapsed and post hoc Scheffe's tests were conducted between groups. There were no differences between the WFDs group and their chronological and language age matches. In contrast both the NA matches $(\mathrm{p}<.001)$ and the RG matches $(\underline{p}<.05)$ were performing significantly poorer than the CA matches.

\section{Latency to name actions}

Mean latencies for correct responses to high and low frequency items are presented in Table 4. There was a significant effect of group $(\mathrm{F}(3,117)=5.98, \underline{\mathrm{p}}<.001)$ and word frequency $\mathrm{F}(1,117)=17.22, \underline{\mathrm{p}}<.001)$ but no interaction. All groups produced high frequency items more quickly than low frequency ones. Since there were no significant interactions between group and frequency, high and low frequency results were collapsed and post hoc 
Scheffe's tests were conducted between groups. The WFDs group were significantly slower than their CA matches $(\mathrm{p}<.05)$. No other significant differences existed between the groups. Nonetheless as shown in Table 4 the children with WFDs were the slowest group to respond for both low frequency and high frequency actions.

\section{Error patterns in naming actions}

Action errors were initially subjected to the same analyses as object errors. Errors were classified as semantic, phonological, don't know responses and other errors. These are presented in Table 6.

\section{INSERT TABLE 6 ABOUT HERE}

As Table 6 shows the overall distribution of error types across the groups was similar, and that other errors were the most common of the four types. As with the object errors there were few phonological errors overall. In contrast to the object errors, for actions children were producing more errors that were categorised as other errors. Since the error data did not meet the requirements of parametric tests the data were analysed with non-parametric tests. Comparisons between the groups using a Kruskal Wallis test revealed no significant differences in the proportion of semantic errors $\left(X^{2}=3.22\right.$, df $\left.=3, \mathrm{~ns}\right)$, don't know responses $\left(X^{2}=1.83\right.$, df $=3$, $\mathrm{ns})$, phonological errors $\left(X^{2}=2.38, \mathrm{df}=3, \mathrm{~ns}\right)$, or other errors produced $\left(X^{2}=1.18, \mathrm{df}=3, \mathrm{~ns}\right)$.

The high proportion of other errors suggested that an important dimension in the children's responses had been missed. When the other errors were further analysed a number of non-target verbs were identified. These included general all purpose verbs such as 'doing' or 'moving', verbs that were similar to the target but incorrect e.g. 'knitting' for 'sewing', and non 
target verbs that were inappropriate e.g. 'swimming' for 'fishing'. These non-target verbs accounted for over 50\% of each group's non-target responses. The proportions of non-target verbs categorised as other errors are presented in table 7

\section{INSERT TABLE 7 ABOUT HERE}

The children with WFDs produced fewer similar but incorrect verbs than their CA matched peers $(U=293.5, \underline{p}<.05)$, NA matched peers $(U=327.5, \underline{p}<.05)$ and $R G$ matched peers $(U=296, \underline{p}<.05)$. Instead the children with WFDs used more non-specific verbs $(U=$ $372, \underline{p}<.05)$ and more verbs that were inappropriate $(U=312, \underline{p}<.05)$ than CA matched peers. These responses did not differ significantly from their language age matches. All these differences in error patterns suggest that, despite their equivalent naming accuracy with CA peers, the semantic domains for children with WFDs were less clearly delineated than their CA peers.

\section{DISCUSSION}

Comparing the performance of children with WFDs with that of chronological and language age controls across a number of measures can extend our understanding of the problems experienced by this group of children. If children with WFDs have a general delay with the lexicon then they would be expected to perform worse than children of the same chronological age but equivalent to children of the same language age. If, however, the children are experiencing a different pattern of development (see Leonard, 1998) we would predict differences between the WFDs and language matched samples. 
Although children with WFDs performed as well as CA controls on comprehension tasks, they did not perform as well as these children in terms of the accuracy of naming. For the naming of low and high frequency objects, the CA group was significantly better than all the other three groups. In other words, for accuracy of object naming the children with WFDs did not differ significantly from their language matched controls. In the case of actions, the pattern of differences was slightly more complicated. The CA group was significantly better than the language matched groups but the performance of children with WFDs was between the highest and lowest scoring groups and their performance was not significantly different from any of the other groups. Thus, the naming accuracy of children with WFDs was equivalent to language matched children for objects and intermediate between CA and LA controls for actions.

The examination of latency of naming reveals yet a third pattern of relations between the performance of children with WFDs and the control groups. Children with WFDs had the slowest responses of all 4 groups on latencies for high frequency objects and for low and high frequency action words. Furthermore, they were significantly slower than CA matches for high frequency objects and for all action words (see Table 2). The difference between children with WFDs and NA matches approached significance for high frequency objects suggesting that there may be a reliable difference between these groups. This trend deserves attention because it suggests that when children with WFDs are matched with typical children on the accuracy of naming (i.e. the BAS naming scale), then children with WFDs are slower than typical children in producing names. Consequently, the children appear to have a specific problem in accessing representations even when they accurately retrieve them.

In contrast to these findings, the latency of responses of children with WFDs to letters and numerals was found to be more similar to the CA group than both the language matched 
groups. This suggests that the longer latencies identified for object words and actions were not simply a product of slower general processing, but this is an issue that needs to be considered in future investigations of the children's difficulties. Further investigations of the differential latencies between accurate, wrong and don't know response have the potential to increase our understanding of the children's strategies for managing their difficulties.

Previous research on children with WFDs has identified high rates of semantic substitution errors (German, 1982; Lahey \& Edwards, 1999; McGregor, 1997). Children with WFDs also appear to produce higher rates of don't know responses than chronological age matched peers in naming tasks (Fried-Oken, 1984; German, 1982; McGregor \& Waxman, 1998). However, our analyses for object errors did not identify any significant differences across groups in the frequency of semantic, don't know or other responses. In contrast the children with WFDs were more likely to make phonological errors. However, this was not true for the action naming. In this case errors were suggestive of less differentiated semantic domains.

Previous studies also have found high levels of phonemic errors (Faust, Dimitrovsky \& Davidi, 1997). This finding is consistent with the argument that children with WFDs can access semantic information but have difficulty accessing phonological information (Constable, Stackhouse \& Wells, 1997). The nature of errors in children with language difficulties has been discussed by Lahey and Edwards (1999) who suggest that phonological errors are characteristic of expressive problems while semantic errors are characteristic of children who have additional receptive problems. In our data for naming objects, children with WFDs produced a higher proportion of phonological errors than the $\mathrm{CA}$ and $\mathrm{RG}$ groups, and this is consistent with the 
idea of a phonological deficit. Nonetheless only $18 \%$ of the errors were phonological and this proportion did not differ significantly from NA matches.

We argued in the introduction that it is of little practical or theoretical interest to apply the term WFDs to children who have general language delays and that it can be useful to compare the performance of these children with a carefully chosen set of matches. The findings from this study provide support for this argument. The analyses that have been conducted suggest that children with WFDs have lexical comprehension skills that are similar to those of typical children of the same age. However, the accuracy of naming of children with WFDs was similar to that of typical children who have the same language level, suggesting that the children are delayed in their naming accuracy. Finally, there was an important trend indicating that speed of naming of children with WFDs for high frequency objects was below that of naming age matched typical children and similar non-significant patterns were evident for the naming of actions. It is important to note that neither of the language matched groups differed significantly from the CA group in latency to respond. Thus, in the naming of objects and actions there appears to be a marked decline in the relative performance for children with WFDs across these 3 different forms of assessment. Any one set of these comparisons could give a very limited and possibly distorted picture of the abilities of children with WFDs, and so these findings reinforce our view that a better understanding of this condition requires a more extensive and careful use of comparison groups.

The comparisons made in this study also have implications for the hypothesis that the semantic representations of children with WFDs are less complex than those of other children and that this results in their having word retrieval problems. In relation to this issue, it is interesting to consider the pattern of performance on items such as letters and numerals with 
items that are more semantically complex such as objects and actions. The crucial comparisons involve determining whether, for a particular set of words, the performance of children with WFDs is similar to that of the comparison groups. In the case of numerals and letters, there were no significant differences between children with WFDs and typical CA matched children in terms of speed and accuracy of naming. Furthermore, children with WFDs were significantly more accurate than typical LA matched peers on numerals and letters. Thus, for the domains of numerals and letters, where it is argued complex semantic representations are not required, the children with WFDs were performing similarly to children of the same age. In contrast, for objects and actions, children with WFDs performed less well than their CA matched controls. Given the low age of acquisition of many of the lexical items employed in this study, it is unlikely that time of exposure can explain the WFDs children's high levels of performance with numerals and letters. Therefore these differences between the set of words are unlikely to be simply due to the amount of time that the children have had to learn the items, and the pattern of differences is consistent with the idea of children with WFDs having impoverished semantic representations.

Comparisons of children's performance on object words and action words, as well as high frequency words and low frequency words, also has a relevance to evaluating the semantic elaboration hypothesis. These comparisons suggest that frequency rather than word type is more influential in determining accuracy. There was, for example, no main effect of word class for accurate naming but there was a main effect of word frequency. Children with WFDs performed significantly less well than chronological aged matched children in naming high frequency objects (see Table 2) and were slower to respond. However, there were no significant differences in corresponding comparisons involving low frequency items. Taken together these 
findings suggest that children with WFDs may experience more problems with lexical items that are relatively well established, rather than items that are likely to be less familiar. Such a pattern of findings is consistent with the idea that the children with WFDs have more problems in building up a complex set of representations than in initially forming these representations, and that as a result they have more problems than matched peers in retrieving these words.

The comparisons also show that across groups, word frequency effects produced similar patterns of results, thereby providing support for the view that the complexity of children's semantic representations influence word retrieval. These results stand in contrast to current research that has highlighted the difficulties with verbs for the language-impaired population (Conti-Ramsden \& Jones, 1997; Fletcher \& Peters, 1984; Tomasello 1992; Watkins, Rice \& Moltz, 1993). However, an examination of the children's errors and latency suggest that there are subtle problems in naming actions for this population. Firstly, there was the greater preponderance of non-verb responses, secondly when verbs were used they were often semantically inappropriate and finally general verbs were used more by the children with WFDs. The latter result is consistent with a reliance on general all purpose verbs that has been reported in the literature about children with language difficulties. Thus, the type of children's errors provide further support the view that part of the difficulties are caused by impoverished semantic representations.

There are, however, two different sources of data that might serve to question the semantic interpretation. The children with WFDs generally had the longest latencies to name objects and actions. Moreover, when we consider their profiles on standardised measures they have particularly low scores on the semantic fluency task in the $\mathrm{PhAB}$, a test that is time limited. This raises the question of whether these children's longer latency to respond can be 
explained by generalised limitations in processing capacity (Kail, 1994; Kail \& Salthouse, 1994; Windsor \& Hwang, 1999). Our present analyses do not directly address this question. Nonetheless, the data indicate that processing limitations per se are not a sufficient explanation of their naming patterns. This is because although children with WFDs had poorer accuracy of naming objects and actions than CA matches, they were not significantly different from CA matches in their latency to name numerals and letters.

Secondly, it is important to consider the comprehension data in more detail. Why was it that children with WFDs were no different from CA matches on comprehension tasks, but slower than CA matches when retrieving the very same words? It often has been argued that retrieval is a more demanding activity than comprehension and Ralli (1999) has provided evidence that children can succeed in comprehension tasks when they either fail to produce a word or provide additional evidence about the word's meaning. Successful comprehension only requires there to be available a partial representation about the relation between the word and the picture. Although our foils were carefully chosen to allow for either phonological or semantic errors, the choices were highly constrained. As a result, we cannot be sure that the children's knowledge about the word's meaning was comparable to that of their CA peers. Even so, it is not unreasonable to suppose that comprehension might be possible with limited representations and consequently, children with WFDs are able to perform almost as well as CA peers on this type of task. Future investigations of these children's representations could be especially valuable (see McGregor, 1999 as an example).

In sum the present data set supports the view that there is a specific group of children who have difficulties in both accuracy and speed of naming relative to their chronological age peers (Wiig, Semel \& Nystrom, 1982) and in certain conditions, relative to their language 
matched peers. Further, these difficulties span different word classes and different word frequencies. There was little direct evidence that the children's difficulties are caused by problems with phonological representations. Both the entry criteria for the study and the nature of the lexical items may have reduced the presence of such effects in the present data set. In contrast, a number of different sources of evidence point to specific problems with the semantic representations for children with WFDs. 


\section{REFERENCES}

Anthony, A., Bogle, D. Ingram, T.T.S. \& McIsaac, M. (1971). Edinburgh Articulation Test. Longman:UK.

Bishop, D.V.M. (1989). Test of Reception of Grammar, $2^{\text {nd }}$ Edition. University of Manchester, The Author, Age \& Cognitive Performance Research Centre.

Bishop, D.V.M. (1997). Uncommon Understanding: Development and Disorders of Language Comprehension in Children. Hove, East Sussex: Psychology Press.

Braisby, N. \& Dockrell, J.E. (1999). Why is colour naming difficult? Journal of Child Language, 26, 23-47.

Burroughs, G.E.R (1957). A study of vocabulary of young children. Birmingham: Oliver Boyd.

Catts, H.W \& Kamhi, A. (1999). Language and Reading disabilities. Boston: Allyn and Bacon.

Chiat, S. \& Hunt, J. (1993). Connections between phonology and semantics: an exploration of lexical processing in a language impaired child. Child Language Teaching and Therapy 9, 201-213.

Constable A, Stackhouse J, \& Wells B. (1997). Developmental word-finding difficulties and phonological processing: The case of the missing handcuffs. Applied Psycholinguistics, $\underline{18}, 507-536$.

Conti-Ramsden, \& Jones, M. (1997). Verb use in specific language impairment. Journal of

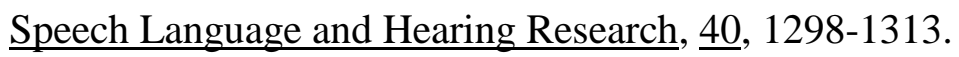

Davidoff, J. \& Masterson, J. (1995/6). The development of picture naming: differences between nouns and verbs. Journal of Neurolinguistics, 9 , 69-93. 
Denckla, M.B. \& Rudel, R. (1976). Naming of object drawings by dyslexic and other learning disabled children. Brain and Language, 3, 1-16.

Dockrell, J.E. Messer, D. George, R. \& Wilson, G. (1998). Children with word-finding difficulties -prevalence, presentation and naming problems. International Journal of Language and Communication Disorders, 33, 445-454.

Dockrell , J.E., Messer, D. \& George, R. (2000) Accuracy and errors in naming objects in children with word finding difficulties. In M.Beers, B.v.d.Bogaerde, G.Bol, J. de Jong \& C.Rooijmans (Eds.) From sound to sentence - studies on first language acquisition . Centre for Language and Cognition, Groningen.

Donaldson, M.L. \& Laing, K. (1993).Children's comprehension of locative expressions. In D. Messer \& G.Turner Critical Influences on Child Language Acquisition and Development. Macmillan: Basingstoke.

Edwards, R.P.A. \& V. Gibbon (1973). Words your children use. London: Burke Press.

Elliott, C.D., Smith, P. \& McCulloch, K. (1997) The British Ability Scales II. Windsor, NFER-Nelson.

Faust, M., Dimitrovsky, L. \& Davidi, S. (1997). Naming difficulties in language disabled children: preliminary findings with the application of the Tip-of-the-Tongue paradigm. Journal of Speech, Language and Hearing Research, 40, 1026-1036.

Fletcher, P. \& Peters, J. (1984). Characterizing language impairment in children: An exploratory study. Language Testing, 1, 33-49.

Francis, W.N. \& Kucera, H. (1982). Frequency analysis of English usage: Lexicon and grammar. Boston: Houghton Mifflin. 
Fredrickson, N., Frith, U. \& Reason, R. (1997). Phonological Assessment Battery. Windsor, NFER-Nelson.

Fried-Oken, M. (1984). The development of naming skills in normal and language deficient children. Doctoral dissertation, Boston University.

Gates A.I., (1935). A reading vocabulary for the primary grades. Bureau of publications, Teacher College, Columbia University. New York.

Gentner, D (1981). Some interesting differences between verbs and nouns. $\underline{\text { Cognition and Brain }}$ Theory, $\underline{4,}$ 161-178.

German, D.J. (1979). Word finding skills in children with learning disabilities. Journal of Learning Disabilities, 12, 43-48.

German, D.J. (1982). Word-finding substitutions in children with learning disabilities. Language, speech and hearing services in schools, 13, 223-230.

German, D.J. (1984). Diagnosis of word-finding disorders in children with learning disabilities. Journal of Learning Disabilities, 17, 353-358.

German, D.J. (1985). The use of specific semantic word categories in the diagnosis of dysnomic learning-disabled children. British Journal of Disorders of Communication, 20, 143-154.

German, D. J. (1989). Test of Word Finding TWF . Chicago Ill., Riverside Publishing Company.

German, D.J., \& Simon, E. (1991). Analysis of children's word-finding skills in discourse. Journal of Speech and Hearing Research, 34, 309-316.

Gilhooly, K.J. \& Logie, R.H. (1980). Age of acquisition, imagery, concreteness, familiarity and ambiguity measures for 1,944 words. Behavior Research Methods and Instrumentation, 12, 395-427. 
Kail, R. (1994). A method of studying the generalized slowing hypothesis in children with specific language impairment. Journal of Speech and Hearing Research, 37, 418-421.

Kail, R., Hale, C., Leonard, L., \& Nippold, M. (1984). Lexical storage and retrieval in language-impaired children. Applied Psycholinguistics, 5, 37-49.

Kail, R. \& Leonard, L.B. (1986). Word-finding abilities in language-impaired children. ASHA Monographs, 25.

Kail, R. \& Salthouse, T. (1994). Processing speed as mental capacity. Acta Psychologica, 86, $199-225$.

Lahey, M. \& Edwards, J. (1996). Why do children with specific language impairments name pictures more slowly than their peers. Journal of Speech and Hearing Research, 39, 1081-98.

Lahey, M. \& Edwards, J. (1999). Naming errors of children with SLI. Journal of Speech, Language and Hearing Research, 42, 195-205.

Leonard, L.B. (1988). Lexical development and processing in specific language impairment. In R. Schiefelbusch \& L.Lloyd (Eds.) Language Perspectives: Acquisition, retardation and intervention. (pp 69-87). Austin TX:Pro-Ed._

Leonard, L.B. (1998). Children with Specific Language Impairment. Cambridge MA: MIT Press.

Markman, E.M. (1989). Categorisation and Naming in Children. Cambridge, MA: MIT Press.

McGregor, K.K._(1999). Semantic representation and developmental word finding deficits. Paper presented at the VIII International Congress for the study of Child Language. San Sebastian, The Basque Country, Spain. 
McGregor, K.K. (1997). The nature of word-finding errors in preschoolers with and without word-finding deficits. Journal of Speech, Language and Hearing Research, $\underline{40}, 1232-44$.

McGregor, K.K. \& Leonard, L. B. (1989). Facilitating the word-finding skills of language-impaired children. Journal of Speech and Hearing Disorders, $\underline{54}, 141-47$.

McGregor, K.K \& Waxman, S. (1998). Object naming at multiple hierarchical levels: a comparison of preschoolers with and without word-finding deficits. Journal of Child Language, 25, 419-430.

McGregor, K.K \& Windsor, J. (1996). Effects of priming accuracy of preschoolers with word-finding deficits. Journal of Speech, Language and Hearing Research 39, 1048-57.

Menyuk, P. (1975). The language-impaired child: Linguistic or Cognitive impairment? Annals of the New York Academy of Sciences, 263, 59-69.

Morrison, C., Chappell, T. \& Ellis, A. (1997). Age of Acquisition Norms for a large set of object names and their relation to adult estimates and other variables. Quarterly Journal of Experimental Psychology, 50, 528-559.

Nippold, M. (1992). The nature of normal and disordered word finding in children and adolescents. Topics in Language Disorders, 13, 1-14.

Ralli, A. (1999). Investigating lexical acquisition patterns: context and cognition. Doctoral dissertation. University of London.

Rapp, B. \& Caramazza, A. (1993). On the distinction between deficits of access and deficits of storage: A question of theory. Cognitive Neuropsychology, 10, 113-141.

Raven, J.C. (1983). Raven's Progressive Matrices. London: H.K. Lewis \& Co. Ltd.

Rescorla, L. \& Schwartz, E. (1990). Outcome of toddlers with expressive language delay. Applied Psycholinguistics, 11, 393-407. 
Rice, M. (1991). Children with specific language impairment: Toward a model of teachability. In N. Krasnegor, D. Rumbaugh, R. Schielfelbusch \& M. Studdert-Kennedy (Eds.). Biological and behavioural determinants of language development. (pp 447-480). Hillsdale, NJ:Lawrence Erlbaum.

Rudel, R., Denckla, M., \& Broman, M. (1981). The effect of varying stimulus context on word-finding ability: Dyslexia further differentiated from other learning disabilities. Brain and Language, 13, 130-144.

Soja, N.N. (1994). Young children's concept of colour and its relation to the acquisition of colour words. Child Development, $\underline{65,918-937 .}$

Snyder, L.S. \& Godley, D. (1992). Assessment of word-finding disorders in children and adolescents. Topics in Language Disorders, $\underline{13}, 15-32$.

Swan, D. \& Goswami, U. (1997). Phonological awareness deficits in developmental dyslexia and the phonological representations hypothesis. Journal of Experimental Child Psychology, 66, 18-41.

Tomasello, M. (1992). First Verbs: A case study of early grammatical development. New York: Cambridge University Press.

Watkins, R., Rice, M. \& Moltz, C. (1993). Verb use by language-impaired and normally developing children. First Language, 37, 133-143.

Wiig, E.H. \& Semel, E.M. (1975). Productive language abilities in learning disabled adolescents. Journal of Learning Disabilities, 8, 578-586.

Wiig, E., Semel, E., \& Nystrom, L. (1982). Comparison of rapid naming abilities in language-learning disabled and academically achieving eight-year-olds. Language, Speech, and Hearing Services in Schools, 13, 11-23. 
Windsor, J. \& Hwang, M. (1999). Testing the generalized slowing hypothesis in specific language impairment. Journal of Speech, Language and Hearing Research, 42, 1205-1218.

Wolf, M. (1980). The word-retrieval process and reading in children and aphasics. Children's Language, 3, 437-490.

Wolf, M. \& Segal, D. (1992). Word finding and reading in the developmental dyslexias. Topics in Language Disorders , 13, 51-65. 
Table 1 Results of Standardised tests used for matching

\begin{tabular}{|c|c|c|c|c|c|c|c|}
\hline & \multirow[t]{2}{*}{$\mathrm{N}$} & \multirow[t]{2}{*}{ Mean Age } & \multirow[t]{2}{*}{$\begin{array}{l}\text { Mean Ravens } \\
\text { centile }\end{array}$} & \multicolumn{2}{|c|}{ British Abilities Naming Scale } & \multicolumn{2}{|c|}{$\begin{array}{l}\text { Test of Reception of } \\
\text { Grammar }\end{array}$} \\
\hline & & & & $\begin{array}{l}\text { Mean Ability } \\
\text { score }\end{array}$ & $\begin{array}{l}\text { Mean Age } \\
\text { Equivalent }\end{array}$ & $\begin{array}{l}\text { Mean Raw } \\
\text { Score }\end{array}$ & $\begin{array}{l}\text { Mean Age } \\
\text { equivalent }\end{array}$ \\
\hline WFDs & 31 & $\begin{array}{c}7 ; 1 \\
\text { (range, } 6 ; 4-7 ; 10)\end{array}$ & $\begin{array}{c}61 \\
\text { (range, } 25-95)\end{array}$ & $\begin{array}{c}77.6 \\
\text { (range, 53-98) }\end{array}$ & $4 ; 10$ & $\begin{array}{c}11.3 \\
\text { (range, } 7-17 \text { ) }\end{array}$ & $5 ; 9$ \\
\hline NA matches & 31 & $\begin{array}{c}5 ; 8 \\
\text { (range, } 3 ; 4-7 ; 3 \text { ) }\end{array}$ & & $\begin{array}{c}77.6 \\
\text { (range, 53-98) }\end{array}$ & $4 ; 10$ & & \\
\hline RG matches & 31 & $\begin{array}{c}7 ; 2 \\
\text { (range, } 4 ; 3-10 \text { ) }\end{array}$ & & & & $\begin{array}{c}11.3 \\
\text { (range, } 7-17 \text { ) }\end{array}$ & $5 ; 9$ \\
\hline CA matches & 31 & $\begin{array}{c}7 ; 2 \\
\text { (range, } 6 ; 5-7 ; 9)\end{array}$ & $\begin{array}{c}58 \\
\text { (range, } 25-90)\end{array}$ & & & & \\
\hline
\end{tabular}


Table 2 - Summary of significant differences between the groups

\begin{tabular}{|c|c|c|c|c|c|}
\hline \multirow{3}{*}{$\begin{array}{l}\text { Letters \& } \\
\text { Numerals }\end{array}$} & \multirow[b]{2}{*}{ CA versus WFDs } & \multicolumn{2}{|c|}{ Comprehension } & Naming & Latency \\
\hline & & & $=$ & $=$ & $=$ \\
\hline & WFDs versus $\mathrm{LA}^{* *}$ & & WFDs $>$ LA & WFDs $>$ LA & $=$ \\
\hline & $\mathrm{CA}$ versus $\mathrm{LA}$ & & $\mathrm{CA}>\mathrm{LA}$ & $\mathrm{CA}>\mathrm{LA}$ & $\mathrm{CA}>/=\mathrm{NA}^{*}$ \\
\hline \multirow[t]{7}{*}{ Objects } & CA versus WFDs & $\mathrm{HF}$ & $=$ & $\mathrm{CA}>\mathrm{WFDs}$ & $\mathrm{CA}>\mathrm{WFDs}$ \\
\hline & & $\mathrm{LF}$ & $=$ & CA > WFDs & $=$ \\
\hline & WFDs versus LA & & & & \\
\hline & & $\mathrm{HF}$ & $=$ & $=$ & LA $\neq$ WFDs \\
\hline & & $\mathrm{LF}$ & $=$ & $=$ & $=$ \\
\hline & $\mathrm{CA}$ versus LA & $\mathrm{HF}$ & $=$ & $\mathrm{CA}>\mathrm{LA}$ & $=$ \\
\hline & & $\mathrm{LF}$ & $\mathrm{CA}>\mathrm{LA}$ & $\mathrm{CA}>\mathrm{LA}$ & $=$ \\
\hline \multirow[t]{8}{*}{ Actions } & CA versus WFDs & $\mathrm{HF}$ & $=$ & \} & \} CA>WFDs \\
\hline & & $\mathrm{LF}$ & $=$ & & \\
\hline & WFDs versus LA & $\mathrm{HF}$ & $=$ & \} & \} \\
\hline & & $\mathrm{LF}$ & WFDs $>$ NA & & \\
\hline & CA versus LA & & & & \\
\hline & & $\mathrm{HF}$ & $=$ & \}$\quad \mathrm{CA}>\mathrm{LA}$ & \} \\
\hline & & $\mathrm{LF}$ & $\mathrm{CA}>\mathrm{NA}$ & & \\
\hline & & & $\mathrm{CA} \neq \mathrm{RG}$ & & \\
\hline
\end{tabular}

** LA (language age) matches refer to the combined pattern for the NA and RG matches when no differences between the language matches occur

* $\quad$ CA $>$ NA for letters, $C A=L A$ for letters

$=\quad$ No significant differences between groups

$>\quad$ Performance of first named group significantly better either in terms of accuracy or speed

$\neq \quad$ Trend for better performance by first named group

\} Analysis collapsed for high and low frequency items, see results section 
Table 3 Correct responses for comprehension and naming of letters and numerals by group

\begin{tabular}{|c|c|c|c|c|c|c|c|c|c|}
\hline \multirow[t]{2}{*}{ TASK } & & \multicolumn{4}{|c|}{ LETTERS (N=5) } & \multicolumn{4}{|c|}{ NUMERALS $(\mathrm{N}=5)$} \\
\hline & Group & WFDs & NA & RG & $\mathrm{CA}$ & WFDs & NA & RG & $\mathrm{CA}$ \\
\hline \multirow{3}{*}{$\begin{array}{l}\text { Compre-h } \\
\text { ension }\end{array}$} & Mean & 4.84 & 3.87 & 4.19 & 5 & 4.94 & 4.23 & 4.68 & 5 \\
\hline & Range & $3-5$ & $0-5$ & $1-5$ & - & $4-5$ & $0-5$ & $1-5$ & - \\
\hline & $\underline{\mathrm{SD}}$ & 0.46 & 1.48 & 1.4 & - & 0.25 & 1.38 & 0.95 & - \\
\hline \multirow[t]{3}{*}{ Naming } & Mean & 4.09 & 2.68 & 3.06 & 4.9 & 4.96 & 3.96 & 4.55 & 5 \\
\hline & Range & $0-5$ & $0-5$ & $0-5$ & $4-5$ & $4-5$ & $0-5$ & $1-5$ & - \\
\hline & $\underline{\mathrm{SD}}$ & 1.46 & 2.15 & 3.38 & 0.3 & 0.18 & 1.67 & 1.15 & - \\
\hline \multirow{3}{*}{$\begin{array}{l}\text { Latency } \\
\text { in seconds }\end{array}$} & Mean & 1.34 & 1.81 & 1.57 & 0.79 & 1.03 & 1.29 & 1.31 & 0.74 \\
\hline & Range & $0.64-5.92$ & $0.6-6.48$ & $0.68-8.32$ & $0.48-1.48$ & $0.64-1.88$ & $0.6-4.72$ & $0.68-8.84$ & $0.48-1.2$ \\
\hline & $\underline{\mathrm{SD}}$ & 0.92 & 1.47 & 1.74 & 0.18 & 0.28 & 0.87 & 1.5 & 0.13 \\
\hline
\end{tabular}


Table 4 Proportion of correct responses for comprehension, naming and latency for correct response by group and frequency

\begin{tabular}{|c|c|c|c|c|c|c|c|c|c|c|}
\hline \multirow[t]{2}{*}{ TASK } & \multicolumn{2}{|l|}{ FREQ } & \multicolumn{4}{|c|}{ OBJECTS } & \multicolumn{4}{|c|}{ ACTIONS } \\
\hline & & & WFDs & NA & $\mathrm{RG}$ & $\mathrm{CA}$ & WFDs & NA & RG & $\mathrm{CA}$ \\
\hline \multirow{5}{*}{$\begin{array}{l}\text { Compre- } \\
\text { hension }\end{array}$} & \multirow[t]{3}{*}{ High } & Mean & 0.97 & 0.96 & 0.97 & 0.99 & 0.99 & 0.96 & 0.97 & 0.99 \\
\hline & & Range & $0.75-1$ & $0.9-1$ & $0.9-1$ & $0.9-1$ & $0.9-1$ & $0.8-1$ & $0.7-1$ & $0.9-1$ \\
\hline & & $\underline{\mathrm{SD}}$ & 0.05 & 0.03 & 0.04 & 0.03 & 0.03 & 0.07 & 0.06 & 0.02 \\
\hline & \multirow[t]{2}{*}{ Low } & Mean & 0.91 & 0.88 & 0.90 & 0.97 & 0.89 & 0.83 & 0.88 & 0.95 \\
\hline & & Range & $0.65-1$ & $0.6-1$ & $0.7-1$ & $0.75-1$ & $0.7-1$ & $0.6-1$ & $0.7-1$ & $0.8-1$ \\
\hline \multirow{6}{*}{$\begin{array}{l}\text { Naming } \\
\text { when } \\
\text { compre- } \\
\text { hension } \\
\text { correct }\end{array}$} & \multirow{3}{*}{ High } & $\underline{\mathrm{SD}}$ & 0.09 & 0.09 & 0.08 & 0.06 & 0.08 & 0.11 & 0.1 & 0.07 \\
\hline & & Mean & 0.88 & 0.86 & 0.87 & 0.93 & 0.87 & 0.78 & 0.85 & 0.92 \\
\hline & & Range & $0.67-1$ & $0.67-1$ & $0.67-1$ & $0.8-1$ & $0.6-1$ & $0.13-1$ & $0.56-1$ & $0.8-1$ \\
\hline & \multirow{3}{*}{ Low } & $\underline{\text { SD }}$ & 0.08 & 0.11 & 0.08 & 0.07 & 0.12 & 0.2 & 0.14 & 0.07 \\
\hline & & Mean & 0.47 & 0.49 & 0.52 & 0.64 & 0.54 & 0.47 & 0.5 & 0.61 \\
\hline & & Range & $\begin{array}{l}0.18- \\
0.75\end{array}$ & $\begin{array}{l}0.18- \\
0.8\end{array}$ & $\begin{array}{l}0.07-0 . \\
85\end{array}$ & $\begin{array}{l}0.2- \\
0.95\end{array}$ & $\begin{array}{l}0.11-0 . \\
89\end{array}$ & $\begin{array}{l}0- \\
0.88\end{array}$ & $\begin{array}{l}0.13-0 . \\
9\end{array}$ & $\begin{array}{l}0.4- \\
0.8\end{array}$ \\
\hline \multirow{7}{*}{$\begin{array}{l}\text { Naming } \\
\text { latency } \\
\text { when } \\
\text { response } \\
\text { correct } \\
\text { in } \\
\text { seconds }\end{array}$} & \multirow{3}{*}{ High } & $\underline{\mathrm{SD}}$ & 0.15 & 0.15 & 0.18 & 0.2 & 0.21 & 0.23 & 0.2 & 0.12 \\
\hline & & Mean & 1.96 & 1.65 & 1.69 & 1.56 & 2.02 & 1.92 & 1.93 & 1.57 \\
\hline & & Range & $\begin{array}{l}1.22-3 . \\
99\end{array}$ & $\begin{array}{l}1.16- \\
2.32\end{array}$ & $\begin{array}{l}1.21-3 . \\
59\end{array}$ & $\begin{array}{l}1.14-2 . \\
12\end{array}$ & $\begin{array}{l}1.31-3 . \\
43\end{array}$ & $\begin{array}{l}1.46-3 . \\
2\end{array}$ & $\begin{array}{l}1.20-4 . \\
06\end{array}$ & $\begin{array}{l}1.27- \\
2.12\end{array}$ \\
\hline & \multirow{4}{*}{ Low } & $\underline{\mathrm{SD}}$ & 0.63 & 0.30 & 0.43 & 0.26 & 0.59 & 0.42 & 0.56 & 0.22 \\
\hline & & Mean & 1.83. & 1.73 & 1.96 & 1.94 & 2.25 & 2.09 & 2.07 & 1.90 \\
\hline & & Range & $\begin{array}{l}0.88-2 . \\
94\end{array}$ & $\begin{array}{l}1.2-2.7 \\
3\end{array}$ & $\begin{array}{l}1.56-4 . \\
06\end{array}$ & $\begin{array}{l}1.93-4 . \\
72\end{array}$ & $\begin{array}{l}1.37-3 . \\
30\end{array}$ & $\begin{array}{l}1.43-3 . \\
15\end{array}$ & $\begin{array}{l}1.05-3 . \\
88\end{array}$ & $\begin{array}{l}1.23- \\
3.07\end{array}$ \\
\hline & & $\underline{\text { SD }}$ & 0.51 & 0.36 & 0.74 & 0.78 & 0.53 & 0.39 & 0.59 & 0.50 \\
\hline
\end{tabular}


Table 5 Proportion of error types for naming objects ${ }^{4}$

\begin{tabular}{lccccc}
\hline Error type & & WFDs & NA & RG & CA \\
\hline Semantic & Mean & 0.60 & 0.62 & 0.59 & 0.62 \\
& Range & $0.25-0.91$ & $0.29-0.90$ & $0.13-0.83$ & $0.00-1.0$ \\
& SD & 0.17 & 0.16 & 0.16 & 0.24 \\
Phonological & Mean & 0.18 & 0.13 & 0.11 & 0.11 \\
& Range & $0.0-0.71$ & $0.0-0.36$ & $0.0-0.40$ & $0.0-0.50$ \\
& SD & 0.15 & 0.11 & 0.11 & 0.13 \\
Don't Know & Mean & 0.21 & 0.25 & 0.24 & 0.25 \\
& Range & $0.0-0.67$ & $0.0-0.71$ & $0.0-0.63$ & $0.0-1.00$ \\
& SD & 0.2 & 0.2 & 0.16 & 0.27 \\
Other errors & Mean & 0.22 & 0.19 & 0.20 & 0.21 \\
& Range & $0.0-0.75$ & $0.0-0.64$ & $0.0-0.63$ & $0.0-0.75$ \\
& SD & 0.18 & 0.14 & 0.17 & 0.19 \\
\hline
\end{tabular}

${ }^{4}$ The sum of all proportions can total more than 1 since children's errors could be classed as both phonological and semantic 
Table 6 Proportion of error types for naming actions ${ }^{5}$

\begin{tabular}{lccccc}
\hline Error type & & WFDs & NA & RG & CA \\
\hline Semantic & Mean & 0.24 & 0.25 & 0.25 & 0.29 \\
& Range & $0.0-0.75$ & $0.0-0.67$ & $0.0-1.00$ & $0.0-.67$ \\
Phonological & SD & 0.21 & 0.18 & 0.26 & 0.16 \\
& Mean & 0.14 & 0.09 & 0.11 & 0.13 \\
& Range & $0.0-0.40$ & $0.0-0.50$ & $0.0-0.33$ & $0.0-0.40$ \\
& SD & 0.13 & 0.12 & 0.11 & 0.14 \\
& Mean & 0.15 & 0.12 & 0.10 & 0.07 \\
& Range & $0.0-1.0$ & $0.0-0.61$ & $0.0-0.60$ & $0.0-0.50$ \\
& SD & 0.24 & 0.18 & 0.16 & 0.14 \\
Other errors & Mean & 0.61 & 0.63 & 0.65 & 0.64 \\
& Range & $0.0-1.00$ & $0.33-1.00$ & $0.0-1.00$ & $0.0-1.00$ \\
& SD & 0.25 & 0.19 & 0.25 & 0.22 \\
\hline
\end{tabular}

${ }^{5}$ The sum of all proportions can total more than 1 since children's errors could be classed as both phonological and semantic 
Table 7 Proportion of non-target verbs categorised as other errors

\begin{tabular}{lcccc}
\hline Error types & WFDs & NA & RG & CA \\
\hline $\begin{array}{l}\text { Same domain but } \\
\text { Different meaning }\end{array}$ & .31 & .44 & .47 & .45 \\
$\begin{array}{l}\text { Inappropriate } \\
\text { General all purpose }\end{array}$ & .22 & .18 & .15 & .08 \\
verbs & .08 & .02 & .01 & .01
\end{tabular}


Appendix 1 Stimuli for naming

\section{A) OBJECTS}

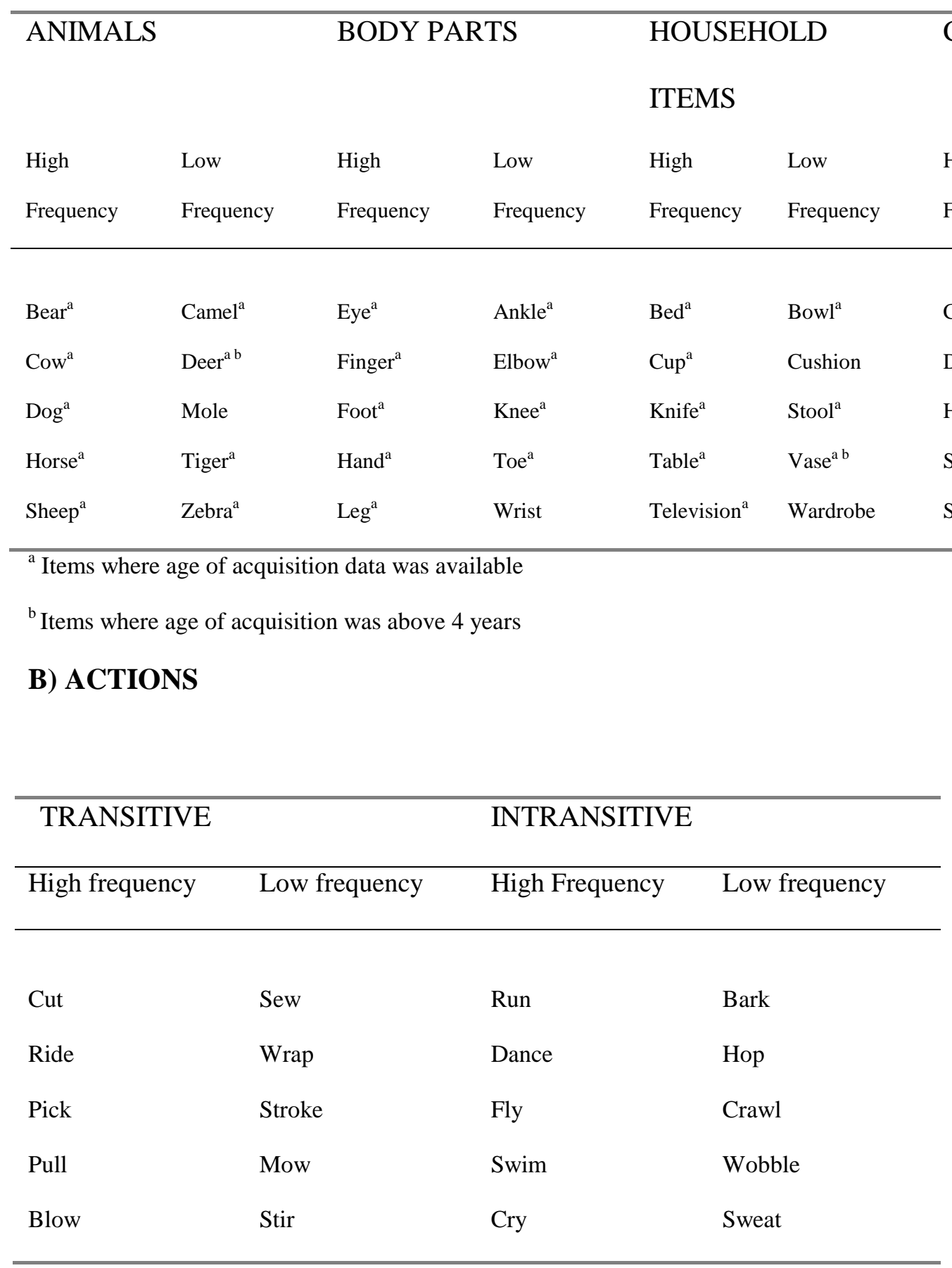

